\title{
Peacekeeping and the Enforcement of Intergroup Cooperation: Evidence from Mali
}

\author{
William G. Nomikos
}

April 16, 2021

\begin{abstract}
Despite the abundance of evidence that peacekeeping works, we know little about what actually makes peacekeepers effective. Recent work suggesting that local agendas are central to modern conflicts make this omission particularly problematic. The article demonstrates that the presence of peacekeepers makes individuals more optimistic about the risks of engagement and the likelihood that members of outgroups will reciprocate cooperation. I use data from a lab-in-the-field experiment conducted in Mali, a West African country with an active conflict managed by troops from France and the United Nations (UN), to show that UN peacekeepers increase the willingness of individuals to cooperate relative to control and French enforcers. Moreover, I find that UN peacekeepers are especially effective among those participants who hold other groups and institutions in low esteem as well as those who have more frequent contact with peacekeepers. Follow-up interviews and surveys suggest that perceptions of the UN as unbiased rather than other mechanisms account for its effectiveness.
\end{abstract}

Keywords: peacekeeping, ethnic conflict, intergroup cooperation, United Nations, lab-inthe-field experiment

Supplementary material for this article is available in the appendix in the online edition.

Replication files are available in the JOP Data Archive on Dataverse (http://thedata.harvard.edu/dvn/dv/jop) and on my website (http://williamgnomikos.com).

This project was approved by Yale University's Institutional Review Board \#1506016057.

Support provided by the Folke Bernadotte Academy, the Weidenbaum Center at Washington University in St. Louis, the Leitner Program, the Institute for Social and Policy Studies, and the MacMillan Center for International and Area Studies at Yale University.

A pre-analysis plan was registered in EGAP \#20160208AA. 


\section{Introduction}

Peacekeeping plays a central role in our understanding of how civil wars end. For instance, enforcement by peacekeepers makes negotiated settlements in civil wars possible, deter belligerents from returning to violence, and promote post-conflict institution-building (Doyle and Sambanis 2006; Fortna 2008). In particular, scholars have highlighted the effectiveness of peacekeepers from the United Nations (UN), noting their ability to contain the spread of violence (Beardsley 2011), limit violence against civilians (Hultman et al. 2020), and forge power-sharing institutions (Nomikos 2020b). While it is clear that UN peacekeepers reduce violence, the mechanisms specifying how they do so in practice are not well understood. This article begins to fill this gap by providing a theory and causally-identified evidence that explains how peacekeepers promote peaceful interactions between individuals on the ground. ${ }^{1}$

Prominent ideas about the effectiveness of peacekeeping mostly focus on how operations shape the behavior of armed groups and their leaders. However, conflict research has increasingly emphasized the centrality of communal disputes between civilians to political violence and successful post-conflict reconstruction (Krause 2018; Carter and Straus 2019). Although scholars have recognized the importance of analyzing the effects of peacekeeping at a sub-national level (Ruggeri et al. 2017; Fjelde et al. 2019) and offered geocoded measures capturing the deployment of peacekeepers (Hunnicutt and Nomikos 2020), much remains to be learned about the how peacekeepers maintain order between everyday citizens of conflict settings. For instance, the deployment of 105 UN peacekeepers in March 2016 to Bouna, a small town in the north-eastern part of Côte d'Ivoire, ostensibly prevented a communal dispute from unraveling a hard-fought and UN-brokered peace. A group of farmers from the Lobi ethnic group had accused cattle herders from the Peulh ethnic group of grazing their

\footnotetext{
${ }^{1}$ I use " peacekeeping" to refer to military or police forces deployed to patrol local communities with a mandate authorizing coercive force. See Appendix E for list of cases.
} 
cows on Lobi land, destroying crops in the process. A series of reprisals and counter-reprisals left more than 20 Ivorians dead and forced thousands to leave their homes in less than a week. ${ }^{2}$ However, the deployed peacekeepers managed to defuse tensions, kept the area stable, and facilitated a return to broad-based cooperation between farmers and herders in Bouna. ${ }^{3}$ What explains the success of peacekeepers in cases of communal dispute such as this? The argument and evidence I put forth here suggests that the Bouna dispute is indicative of broader patterns of the ability of UN peacekeepers to enforce peaceful interactions between civilians in post-conflict settings.

Specifically, this article advances a theory that peacekeepers increase the willingness of individuals to cooperate across social groups by shaping how they perceive the risks from engaging in cooperation. I present a straightforward decision framework in which an individual's willingness to cooperate in the short-term is a function of their beliefs about whether or not others will reciprocate that attempt at cooperation. I argue that peacekeepers shape these beliefs in systematic ways. In particular, the presence of peacekeeping patrols makes individuals more optimistic in their perceptions of the risks of engagement and about the likelihood that members of outgroups will reciprocate their attempts at cooperation. Through this mechanism, international peacekeepers make residents of post-conflict settings more willing to cooperate across group boundaries.

I test this argument with a pre-registered lab-in-the-field experiment carried out in Mali, a West African country with ongoing communal conflicts managed by troops from the UN and France. Identifying the causal effect of peacekeeping with observational data is challenging because patrols typically deploy to areas with limited prospects for intergroup cooperation. An observational analysis would be unable to separate the effect of international patrols from the characteristics of these locations, such as a history of hostile intergroup interactions. A

\footnotetext{
2 "Côte d'Ivoire: au moins 20 morts dans des affrontements à Bouna," RFI Afrique, March 25, 2016.

3 "Security Council Presidential Statement Marks Withdrawal of United Nations Operation in Côte d'Ivoire, Affirms Continuing Partnership in Next Phase," June 2017.
} 
lab experiment is particularly well-suited as an alternative empirical approach because it allows for observation of actual cooperative behavior under circumstances that do not introduce additional factors that may bolster or undermine cooperation. To measure willingness to cooperate, I recruited participants to play a trust game in which they are told to send money to an anonymous partner from a different ethnic group. I randomly assign participants to a control group or one of two treatment groups in which they are told that two patrolling officers from either the UN or France will punish any low partner contributions with a fine. To identify the effect of peacekeeping, I compare the amount participants send in the control group to the two treatment groups.

The evidence shows that some, but not all, types of peacekeeping has a strong positive effect on the willingness to cooperate in a post-conflict setting. Whereas the UN treatment increased willingness to cooperate by $32.7 \%$ relative to control, the France treatment had no substantive or statistically significant effect. I find that UN peacekeeping is especially effective among individuals with little other reason to cooperate - those with low social trust, little contact with members of other ethnic groups, and low trust in formal governance institutions. I also present some evidence that the UN is relatively more effective among individuals who have had previous interactions with peacekeepers compared to those who have not. Perceptions of the UN's ability and willingness to intervene in an everyday interaction relative to France likely drive these divergent effects. Follow-up interviews and surveys suggest that the idea of the UN as unbiased may be the most important channel through which the UN increases willingness to cooperate. This provides an important link between cross-national evidence documenting the effectiveness of UN peacekeeping operations and studies that emphasize the positionality of an international intervener as foreign (Lyall et al. 2013; Lake 2016). The results further imply that residents of post-conflict settings may reject the presence of some international actors more than others and that this may have real effects on peacekeeping outcomes. 
This article extends existing research on the conditions under which the international community can reduce the fragility of post-conflict settings (Beath et al. 2012; Crost et al. 2014; Sexton 2016; Lyall et al. 2020). The findings of this study suggest that peacekeepers, deployed with the explicit mandate to enforce peaceful interactions within civilian communities, can promote intergroup cooperation in weakly institutionalized settings. Existing scholarship on intergroup cooperation has explored the effect of factors such as in-group policing (Fearon and Laitin 1996), exposure to violence (Gilligan et al. 2014), national identity (Charnysh et al. 2015), and international aid (Fearon et al. 2015) but has devoted considerably less attention to the effect of peacekeeping operations. Intergroup cooperation limits communal violence, promotes economic development, and bolsters social trust. For these reasons, it is important to examine how international actors can encourage citizens of post-conflict societies to cooperate across group boundaries.

\section{A Micro-Level Theory of Intergroup Cooperation under Peacekeep- ing}

In the aftermath of civil wars, individuals, families, or clans living in the same community struggle to sustain cooperation over local issues such as cattle herding, land use, or the value of goods. ${ }^{4}$ Individuals living in post-conflict settings must assess several parameters before choosing to cooperate across group boundaries. The expected utility of choosing to cooperate involves weighing the material and social benefits of intergroup cooperation against the costs, which are a function of the probability that a potential partner will choose to reciprocate cooperation and the risk that a potentially straightforward interaction may escalate into violence. Limiting cooperation to members of an in-group serves as a rudimentary yet invaluable survival technique. Coethnicity may be especially useful in identifying trustworthy partners (Habyarimana et al. 2009). Alternatively, cooperation may be a direct function of how individuals interpret each other's motives (McCabe et al. 2003). Individuals in a

\footnotetext{
${ }^{4}$ I refer to disagreements arising over such issues as "communal" or "local-level" disputes (Krause 2018).
} 
society may earn reputations for trustworthiness or norms for reciprocity may dominate in a community, dictating how individuals should return cooperative action (Berg et al. 1995).

For residents of post-conflict settings, intergroup cooperation may not be worth the risk at all. Civil wars destroy state capacity, limit the efficacy and legitimacy of domestic institutions, and rip apart the social fabric that connects individuals to one another, making intergroup cooperation an unlikely prospect. Domestic state police and security institutions can promote cooperation in multi-groups settings by punishing those who take advantage of individuals that try to cooperate, thereby increasing the probability that partners will reciprocate. When conflict eradicates the limited capacity and legitimacy of these institutions, they cannot intervene in intergroup interactions in order to limit the risk that the interactions become violent. Preference for an in-group member over an out-group member will only increase as cooperation with an out-group becomes riskier. Intergroup violence hardens ethnic cleavages, making individuals more likely to identify with parochial in-groups and less likely to extend cooperation to members of out-groups.

Peacekeepers increase an individual's willingness to cooperate by increasing the perceived probability that their partner will reciprocate cooperation. Hypothesis 1 summarizes this prediction. $^{5}$ International actors - organizations, regional alliances, or countries-deploy troops to patrol villages, towns, and neighborhoods of cities to enforce peaceful interactions between members of different social groups. These peacekeeping patrols encourage cooperation through the punishment or threat of punishment of individual violations of the law. Either in collaboration with domestic police forces, traditional authorities, civil society leaders, or community leaders or on their own, peacekeepers interact with civilians, learn about ongoing disputes in a locality, and attempt to stop such disputes from escalating.

Hypothesis 1 Peacekeepers increase individuals' willingness to cooperate with members of

\footnotetext{
${ }^{5}$ I pre-registered the hypotheses with Evidence in Governance and Politics (EGAP). In Appendix F, I re-produce an anonymized version of the pre-analysis plan.
} 
other groups.

Peacekeeping at this level is a question of deterrence. Peacekeepers do what domestic security institutions are unable or unwilling to do-draw a clear line between violence used in intergroup interactions and the punishment of such violence. The message to locals is that if they use violence, peacekeepers will respond in kind or detain them. Even when disputes are far from violent, the presence of peacekeepers discourages aggression that may lead to bloodshed. In so doing, peacekeeping patrols deployed to post-conflict settings lay the foundation for intergroup cooperation at the local level.

As an example, consider the duties of Gladys Ngwepekeum Nkeh, a Cameroonian officer in the UN police (UNPOL) force deployed as part of the UN Multidimensional Integrated Stabilization Mission in the Central African Republic (MINUSCA). During one of her daily patrols in a neighborhood of Bangui, the capital of the Central African Republic, Nkeh discovered that a resident of the neighborhood had raped a thirteen-year-old girl. In a state with limited security and judicial institutions, events like this rape can begin a cycle of retaliation and counter-retaliation between families and members of a community. Instead, Nkeh and her UNPOL contingent quickly apprehended a suspect, helping bring him to justice swiftly. ${ }^{6}$ Knowing that a security officer like Nkeh exists and is active in enforcing interactions can bolster cooperation between individuals, families, and ethnic groups.

The effectiveness of peacekeepers as local-level enforcers is a function of the identity and type of international actor doing the enforcement. Hypothesis 2 articulates this logic formally. Indeed, existing research has offered several reasons why the UN rather than individual countries is particularly well-suited to promoting peace at the local level. First, domestic populations may perceive the UN to be less biased than patrols from individual countries. International organizations such as the UN operate without a legacy of colonial rule (Abbott and Snidal 1998; Bush and Prather 2018), which domestic populations almost

\footnotetext{
6 "Meet Gladys Nkeh, a UN police officer in the Central African Republic," UN News, October 24, 2017.
} 
universally associate with favored minority groups (Tambiah 1989; Posner 2005). Such a history might make locals hesitant to believe that an international peacekeeper from a former colonial power would intervene on their behalf if a non-cooperative partner was from a favored group. Second, multidimensional UN peacekeeping deployments possess substantial operational capacity, with an annual budget in excess of $\$ 1$ billion and 10,000 troops for operations in countries like Mali, the Central African Republic the Democratic Republic of Congo, and the South Sudan (Howard 2019). As the logic goes, the more well-outfitted troops there are in a given locality, the more operational resources peacekeepers have to enforce local-level peace (Ruggeri et al. 2017) Additionally, UN peacekeepers deploy more widely than limited unilateral foreign interventions, collecting information about social interaction information through daily patrols around a locality. Having information about these interactions, including the setting in which the dispute takes place, facilitates the UN's efforts to promote intergroup cooperation (Gordon and Young 2017).

Hypothesis 2 Peacekeepers from the UN increase individuals' willingness to cooperate with members of other groups more than peacekeepers from single countries.

The scope of this hypothesis includes only the UN among international organizations but any country conducting a military intervention in a post-conflict setting for several reasons. Unlike regional organizations such as the African Union or the Economic Community of West African States (ECOWAS), UN peacekeepers use force solely in self-defense or to protect civilians. Moreover, other regional organizations such as the European Union or NATO are dominated by Western, colonial powers and perceived accordingly. Indeed, as an empirical matter, former colonial powers account for the vast majority of unilateral military interventions in existing conflicts in Africa (for example, the United Kingdom in Sierra Leone or France in Cote d'Ivoire). However, even if an intervention is conducted by a non-colonial major power such as the United States or a historically neutral power such as Sweden, it is highly improbable that locals will perceive their troops as unbiased for 
long. Countries typically launch military operations in alliance with local ethnic groups, leading to the wider population associating the foreign interveners with those ethnic groups (Sambanis et al. 2012). And even if populations do not initially perceive interveners as biased, local groups will see international violence as a sign of bias against them (Lyall et al. 2013).

My argument is that in the context of communal disputes, deterrence is the primary but not only channel through which peacekeepers keep the peace. I acknowledge that peacekeeping troops project power in other ways (Howard 2019) and that they resolve communal disputes using civilian programming as well (Smidt 2020). Rather, I suggest that the mechanisms that explain the effectiveness of peacekeeping operations at the local level differ fundamentally from those at the country level. For example, peacekeepers operating within communities do not create physical buffer zones to separate disputing parties, as is critical to success when deploying in the midst of fighting between armed group (Hultman et al. 2020). Though existing research has found that cultural distance between international peacekeepers and domestic populations decreases battlefield performance (Bove and Ruggeri 2019), I argue that distance may actually be beneficial at the local-level since it sustains the perceptions that peacekeepers are unbiased. Nonetheless, the logic of my argument does align with the idea that in the absence of a third-party enforcer ethnic groups will not cooperate because of an inability to credibly commit to an agreement (Walter 2002). In this sense, peacekeepers can help solve commitment problems that arise between civilians just like they do between leaders of armed groups (Hultman et al. 2020).

I also argue that peacekeeping at the local level is at its most effective when baseline (i.e., pre-treatment) levels of intergroup and social trust are low. It is under these conditions that enforcement is needed the most since members of two different social groups will have little reason to trust each other enough to cooperate. Moreover, if an individual trusts a potential partner enough, external enforcement of uncooperative behavior might not be not 
necessary since they believe that the partner will reciprocate any attempts at cooperation. It is unlikely that peacekeepers have a significant effect on such interactions.

Hypothesis 3 Peacekeepers increase the willingness to cooperate with members of other groups more among individuals with low levels of trust than those with high levels of trust.

Finally, I posit that the more individuals interact with peacekeepers, the more likely they are to trust their enforcement commitment and trust that any potential interactions with members of other groups will be policed. Although limited data exists about the interactions between civilians and peacekeepers, research suggests that UN bases may increase economic activity (Mvukiyehe and Samii 2010) and that UN peacekeeping patrols may strengthen perceptions of state authority (Blair 2019). In fact, prominent critiques argue that UN peacekeepers should interact more, not less with local populations (Autesserre 2015). Although contact should have a trust-building effect, it is also possible that any positive effects would be offset if locals perceive the intervention to be neo-colonial. This negative effect is likely exacerbated when peacekeepers come from a single country. Nonetheless, existing work has demonstrated that international peacekeepers can build fruitful relationships with local populations through increased contact (Gordon and Young 2017).

Hypothesis 4 Peacekeepers increase the willingness to cooperate with members of other groups more among individuals with whom they have frequent contact than those with whom they have infrequent contact.

It is important to recognize the limits of this argument. Because the main mechanism relies upon deterrence from the presence of peacekeeping patrols, the theory cannot predict whether cooperation continues after the withdrawal of peacekeeping operations. Selfenforcing institutions do not automatically emerge in the absence of an international actor (Beardsley 2008). Indeed, many of the challenges that peacekeeping operations have faced in the past two decades reflect this dynamic. Intergroup cooperation will dissipate when 
peacekeepers withdraw unless there is substantial development of domestic institutional capacity. It is for this reason that most modern UN peace operations have become long, drawn-out affairs, even after nominal peace treaties have been signed. The length of peacekeeping operations in Liberia (2003-2018) and Cote d'Ivoire (2003-2017), both considered successes within the UN, reflect the inherent challenges of building sustainable institutions in the long-term. In the Democratic Republic of Congo and Darfur, the UN has spent more the fifteen years with little to show in terms of state capacity. Nonetheless, by bolstering intergroup cooperation in the short-term, peacekeepers can give post-conflict societies time to build institutions and lay the foundation for long-term peace.

\section{Peacekeeping and Intergroup Conflict in Mali}

I test the hypotheses in Mali, a landlocked West African country with several ongoing conflicts managed by French and UN troops. At the time of research, France and the UN had both deployed patrols to promote local-level cooperation between members of different social groups. This confluence of events offered a unique opportunity to study how residents of a post-conflict setting in which identity-based disputes are highly salient respond to peacekeeping without jeopardizing the safety and security of research participants and staff.

A long history of intergroup tensions characterizes the socio-political context of the study. Relations between the Tuareg ethnic minority, numbering about 400,000 (almost 2\% of Mali's population) and Mali's dominant "Mandé" 7 ethnic groups structure Malian politics. ${ }^{8}$ After independence from France in 1960, the Mandé-based central government refused to grant the Tuareg their own independent state. Instead, the new government enacted policies to make Mali a purely Mandé nation-state (Jones 1972). In response, Tuareg leaders launched rebellions against the central government in 1963, 1990, 2006, and 2012 (Wing 2013).

A coalition of major Tuareg armed groups signed a peace accord with the government to

\footnotetext{
${ }^{7}$ Mandé denotes a culture shared by a majority of Malians (Conrad and Conde 2004).

${ }^{8}$ Couisinage does not extend to Mandé-Tuareg relations (Dunning and Harrison 2010).
} 
formally end the most recent round of hostilities in June 2015 (Pezard and Shurkin 2015). Nonetheless, relations between ethnic groups remain poor. With overextended local police, abusive domestic military forces, and a corrupt court system, the Malian state cannot enforce the rule of law. Farmers, traders, and cattle herders instead call upon armed groups or selfdefense militias to settle local scores and resolve communal disputes. Intergroup trade has become dangerous and has decreased dramatically. Malians report a sense of helplessnessthey want to trade but fear being taken advantage of or worse (Human Rights Watch 2017).

In response to growing communal tensions, France and the UN have both deployed forces to promote intergroup cooperation within communities. Following military intervention to combat growing violent extremism in the region (Operation Serval and Operation Barkhane), France has deployed patrols to rural areas in northern and central Mali with the specific goal of preventing communal disputes (Gillier 2015). The United Nations Stabilization Mission in Mali (MINUSMA) employs military and police forces that look to prevent the escalation of disputes before they occur. MINUSMA short-range patrols target communities, providing them with an opportunity to report crimes and to register local grievances. For example, UN police in major population centers have routine, daily patrolling routes that they use to monitor ongoing interactions and disputes between Malians from different ethnic groups. Additionally, MINUSMA deploys long-range patrols that accompany Malians to weekly markets outside of major population centers to encourage trade and protect them from intergroup predation. ${ }^{9}$ For instance, UN patrols in northern Mali routinely accompany cow herders to markets outside of secure city centers to make sure that the herders or the farmers they interact with at these markets do not cheat or steal from their trading partners, who are frequently from another ethnic group.

I carried out the study in February-March 2016. At this time, the ethnic conflict between Tuareg separatists and the Malian government had receded as a threat to the stability of

\footnotetext{
${ }^{9}$ Author interview with MINUSMA Police Commissioner, August 3rd, 2016.
} 
Mali, replaced instead by pockets of communal violence driven by breakdowns in cooperation (Nomikos 2020a). Peacekeeping patrols looking to prevent these breakdowns are likely less effective in Mali than they would be in other settings, making Mali a difficult test for the main hypothesis (Hypothesis 1). As one of Africa's poorest and most underdeveloped states, Mali lacks the institutional and infrastructural capacity to support large peacekeeping operations that rely on domestic roads, bases, and airfields to deploy troops where needed. The size, demographics, and geography further complicate the efforts of peacekeeping patrols to project power-Mali is one of Africa's ten largest and least densely populated states, more than half of Mali's land area is covered by the Saharan desert, and a large mountain range on the northern border with Algeria provides ideal hiding places for violent actors.

Moreover, Mali is an especially difficult test case for the effectiveness of UN peacekeepers as international enforcers (Hypothesis 2). Because French and UN troops deployed at nearly the same time, in similar areas, and often carry out similar missions, civilians occasionally do not distinguish between the two. UN peacekeepers thus have fewer distinct advantages in Mali than in other settings where a division of labor between international actors may be clearer. Since the deployment of the UN in 2013, more peacekeepers have died in Mali than in any other peacekeeping operation, often in high-profile setbacks that make national news in Mali. For example, during the first week of the study, extremists hit a UN base with mortars, gunfire, and a truck bomb, killing five and wounding thirty more (Diallo and Diarra 2016). For these reasons, I expect the findings presented in the paper to generalize to other conflict settings with international peacekeeping operations.

\section{Research Design: Identifying the Effect of Peacekeeping}

Testing the argument that peacekeepers increase individual willingness to cooperate with members of outgroups requires isolating the effect of peacekeeping from two primary threats to identification. First, the effect of peacekeeping must be isolated from characteristics of 
the local context that may inhibit or bolster cooperation. For example, peacekeepers deploy to violent and unstable areas where intergroup cooperation is difficult to sustain, resulting in a spurious negative correlation between peacekeeping and cooperation. As Figure B1 in the Appendix shows, this issue is particularly severe in Mali-the UN deploys to the most violent areas of the country.

Second, the effect of peacekeeping patrols enforcing an interaction must be isolated from the effect of information generated by the circumstances surrounding that interaction. Each exchange between members of different social groups introduces new information that likely affects whether an individual will want to cooperate or not, making it difficult to disentangle the effects of this new information from the effects of peacekeeping enforcement. For instance, a cattle herder may meet several members of their community in a weekly market patrolled by peacekeepers, choosing ultimately to sell the meat from some of their cows after several peaceful interactions. Using solely observational data, we may come to the premature conclusion that the peacekeeping patrols increased the willingness of the cattle herder to cooperate. Yet, it would not be clear whether the herder cooperated because of the presence of the peacekeepers or new information about their fellow community members gathered during the weekly market.

In order to address these two threats to identification, I implemented a lab-in-the-field experiment in February and March 2016 designed to elicit cooperative behavior from nonTuareg Malians toward Tuareg partners. In the fashion of a trust game, I tasked participants with sending a part of an initial salary to a Tuareg partner that they then had to trust would reciprocate the attempt at cooperation (Berg et al. 1995; McCabe et al. 2003). In order to address the first threat to identification, I randomly assigned participants to a control group or one of two peacekeeping treatments so that any potential characteristics of the area of the study would be independent from the effect of enforcement. If assigned to a treatment, I informed participants that a peacekeeper, either from the UN or France, would observe and 
fine low contributions, a common method from experimental psychology to operationalize the presence of a third-party enforcer (Fehr and Fischbacher 2004; Bernhard et al. 2006). To deal with the second threat to identification, I kept characteristics of the interaction between the participants the same across treatment groups. Therefore, any differences between the treatment and control groups can only be attributed to the effect of the treatment groups, not new information that arises over the course of the social encounter.

\section{Protocol}

Four mobilizers recruited participants to come to a central location where one of eight enumerators would meet a participant and explain the rules of the game. A local field manager provided each participant a briefing before the game and debriefing after the game to ensure full comprehension. The safety of the participants and local enumerators was of utmost importance to me. I did not wish to expose my subjects to any unnecessary risk, judgment, or actual punishment based upon their behavior in my study. And so, I did not invite real peacekeepers or Tuareg Malians to participate in the game. I discuss the ethical ramifications of this decision in Appendix B.5. The protocol of the game was as follows:

1. Enumerators gave participants 1,000 West African francs (FCFA) in an envelope, some of which they are tasked to donate (denoted $y$ in the game).

2. Enumerators showed each participant a picture of their partner in the game - a Tuareg man - and told them his name and ethnicity to make sure that they understood that they were interacting with someone from the Tuareg ethnic group.

3. Participants were randomly assigned to no enforcement (control), UN peacekeeping, or French enforcement.

4. Enumerators told the participants that the study organizers would double however much they send for a maximum of $2,000 \mathrm{FCFA}(2 y) .{ }^{10}$

5. Participants are also told that the Tuareg partner would choose to keep between 0 and 2,000 FCFA for themselves $(x)$ and send back only the remainder $(2 y-x)$.

\footnotetext{
${ }^{10}$ The doubling provides a non-altruistic incentive to send some of the initial endowment.
} 
6. If the participants were assigned to UN or French peacekeeping, the enumerators explained that two peacekeepers in another room in the building would look at both contributions and assess a fine of 500 FCFA if they considered either amount low. ${ }^{11}$

7. Enumerators left the participants alone to decide how much to send.

8. Enumerators returned to collect the envelope and the game ended.

The principal outcome of interest in the lab experiment is the amount (out of 1000 FCFA) that the non-Tuareg Malian participant decided to send to her Tuareg partner. I use the amount sent to operationalize willingness to cooperate - the greater the amount sent, the greater the willingness to cooperate across group boundaries. The doubling of the amount sent by the non-Tuareg participant (out of 1,000 FCFA) provides a material incentive for individuals to choose to cooperate. It makes evident that mutual cooperation in the game may lead to greater rewards than simply keeping the initial endowment. ${ }^{12}$ Moreover, the doubling reflects real life interactions where there are concrete gains from cooperation that do not exist otherwise. However, as in reality, the willingness to send that amount and cooperate is conditional on whether participants believe that the Tuareg partner will reciprocate their efforts, making cooperation worth their while. The presence of third-party enforcement affects beliefs about Tuareg willingness to participate. By comparing how much participants sent in the treatment groups (UN and France) to the control group, I can quantify in a controlled environment the degree to which peacekeepers increase willingness to cooperate.

\section{Formalization of the Trust Game}

I develop the simplest possible game theoretic model that allows analysis of the circumstances where a non-Tuareg's optimal strategy is to cooperate with their Tuareg partner. ${ }^{13}$ The game

\footnotetext{
${ }^{11}$ I designed the game not to specify what constitutes a low amount to reflect the real-life uncertainty among local populations surrounding the willingness of peacekeepers to act.

${ }^{12}$ Although altruistic motivations likely factored into the decision-making calculus of some participants, randomization ensures that these motives are balanced across treatment groups.

${ }^{13}$ Although this game is not without loss of generality, I analyze a more general version of the game in Appendix $\mathrm{C}$ to demonstrate that the main implications remain the same.
} 
has the structure depicted in Figure C1 in the Appendix. First, Nature assigns a probability $p_{y}$ with which the non-Tuareg player (denoted $M$ ) will face third-party enforcement. Second, $M$ decides an amount $y \in[0,1000]$ to send to their Tuareg partner (denoted $T$ ). The third party enforcer fines $M$ by 500 if the share of the contribution sent over is smaller than the enforcer's cut-point $(c \in[0,1])$ with probability $p_{y}$. After the second stage, the amount is doubled to $2 y$. Third, Nature assigns a probability $p_{x}$ with which $T$ will face third-party enforcement (assumed to be the same as before). Fourth, $T$ decides an amount $x \in[0,2 y]$ to return to $M$. The third-party enforcer fines $T$ by 500 if the share of the contribution sent over is smaller than the enforcer's cut-point $(c)$ with probability $p_{x}$.

I model treatment assignment as changing values of $p_{x}$ and $p_{y}$. Another way to think of the probability parameters $p_{x}$ and $p_{y}$ reflect the probability that a bias in favor of either $M$ or $T$ exists and that the parameter $c$ represents the magnitude of that enforcer's bias. When either probability parameter is less than 1, players will perceive with increasing likelihood that the enforcer is biased and unlikely to punish enforcement. ${ }^{14}$ Neither player faces the fine so $p_{y}^{\text {Control }}=p_{x}^{\text {Control }}=0$. Under the UN treatment, both players face the fine so $p_{y}^{U N}=p_{x}^{U N}=1$. Finally, under the France treatment, only $M$ will face the fine so $p_{y}^{\text {France }}=1$ but $p_{y}^{\text {France }}=0$. Since I do not tell the participants in the experiment the cut-point at which the enforcers will actually fine them, I do not make any assumptions about $c$. If there is no third-party enforcer present (control), the players only receive what their partners send and what they choose to keep before sending. For $M$, this is $1000-y-x$. If the UN is present, both players must now take into account that the UN will fine them if their contributions are low $(y<1000 \cdot c$ for $M)$. However, if France is present, only $M$ faces a fine if her contributions are low.

\footnotetext{
${ }^{14}$ I present the model under the assumption that beliefs about bias are total-France will never punish the Tuareg while the UN will. I relax this assumption explicitly in Appendix C.5 to show that as long as the the probability that France will punish the Tuareg is lower than the UN, results hold.
} 
Table 1: Summary of baseline expectations from game

\begin{tabular}{ccccc}
\hline \multicolumn{2}{c}{ Treatment } & Tuareg best response & & Non-Tuareg Player action \\
\hline No enforcement & $p_{x}=p_{y}=0$ & 0 & $\Rightarrow$ & 0 \\
UN enforcement & $p_{x}=p_{y}=1$ & $2 y \cdot c$ & $\Rightarrow$ & $1000 \cdot c$ if $c<\frac{1}{2}$ \\
& & $\Rightarrow$ & $\frac{250}{c}$ if $c \geq \frac{1}{2}$ \\
French enforcement & $p_{x}=0, p_{y}=0$ & & \\
& & & $\Rightarrow$ & $1000 \cdot c$ if $<\frac{1}{2}$ \\
& & $\Rightarrow$ & 0 if $c \geq \frac{1}{2}$ \\
\hline
\end{tabular}

I use the subgame perfect equilibrium (SPE) refinement to analyze the game. Once assigned to treatment, players have complete and perfect information so there is a unique equilibrium for any distribution of the model's parameters. Table 1 summarizes the equilibrium conditions for the Tuareg and Non-Tuareg player. It reflects the logic of backward induction, with each row representing a possible equilibrium path of play under different treatments. The column on the left lists each of the three treatment conditions and the probability parameters for each of those treatments. The middle column states the best response of the Tuareg player in each of the three treatment conditions. The column to the right lists the action of the Non-Tuareg player in each treatment condition respectively.

The Non-Tuareg player's action hinges on their beliefs about enforcement. Figure C2 in the Appendix depicts the range of parameters for which the Non-Tuareg player is willing to cooperate (i.e., $y>0$ ). For all possible values of $c$ under no enforcement, the Non-Tuareg player will choose to send nothing. Under UN enforcement, the non-Tuareg player will always choose to send something. Under French enforcement, the non-Tuareg player is only willing to cooperate when the costs to doing so are relatively low $(c<0.5)$. Analysis of the model's equilibrium allows us to draw empirical implications for the lab experiment. In the experiment, I vary the value of $p_{x}$ and $p_{y}$ by randomly assigning participants to the three 
treatments but I do not tell them anything about the magnitude of the cut-point, $c$. All else equal, the probability that the non-Tuareg participant will cooperate should increase when assigned to UN enforcement compared to both no enforcement and French enforcement. Specifically, we should expect that assignment to the UN treatment will increase the size of the Non-Tuareg contribution on average relative to the other treatments.

\section{Sampling Procedure}

I drew a sample of 512 non-Tuareg Malians from eight randomly selected neighborhoods of southeast Bamako, a semi-urban and residential part of the capital city of Mali. I sample from this part of Bamako to minimize the differences between Bamako and other areas of Mali. This sample is representative of residents in Bamako. However, it is not representative of all residents of Mali in two respects. First, even in these residential areas, the proximity to the center makes life substantially different than it is for rural residents of Mali. Second, the ethnic make-up of the sample differs between Bamako and the rest of Mali, with Tuareg representing a smaller share of the population in Bamako than in Northern Mali, for instance. To the extent that this study focuses on non-Tuareg Malians, this is less of an issue.

The average participant was 26 years old, has two children, and has completed middle school. Only half of participants were Bamako natives and about half have a close friend who is Tuareg. About $34 \%$ of the participants said that they were members of the Bambara group, the largest ethnic group in Mali, similar to levels across Mali according to the most recent census. The only severe sampling issue that arose was that the mobilizers undersampled women. Although this limits the ability to generalize some of my findings, cultural considerations made sampling women very difficult. In particular, very few women were willing to leave their neighborhoods and come to the location of the experiment. In Appendix D.2, I analyze solely the responses of the women in my sample to investigate this issue further. Balance tests do not indicate any failures in the randomization procedure (see Appendix B.1). 
One exception is that participants assigned to the France treatment said that they come into contact with UN patrols more frequently than those assigned to the UN treatment. I adjust for this imbalance in Appendix D.1 and find that it does not affect the main results.

I chose Bamako as the setting for the lab experiment for three reasons. First, the UN has its main military and police headquarters in Bamako. Participants will likely be familiar with the UN peacekeeping mission. Survey question responses from the experiment confirm this. $68 \%$ report seeing UN peacekeepers "all the time" or "often." Only $2 \%$ report never having seen them. As such, Bamako offers the lab experiment a high degree of internal validity. That is, given the awareness of the UN, the observed treatment effects are likely to operate as theorized. Second, since 2012, violence in northern and central Mali has forced internally displaced Tuareg to take up residence in Bamako. This migration has not only diversified neighborhoods in Bamako but also heightened communal tensions between Tuareg and nonTuareg in the area. Finally, the attacks on the Radisson Blu hotel in November 2015, the first of their kind since the June 2015 peace accords, likely increased the salience of violence for respondents at the time of the experiment. Shortly after the conclusion of the experiment, armed groups attacked the EU training mission in Bamako. Moreover, the frequent attacks on UN peacekeepers and surrounding populations make for ubiquitous headlines in Bamako. These factors make Bamako an active test case of local-level peacekeeping in Mali.

\section{Results}

This section presents tests of whether the peacekeeping treatments increase participants' willingness to cooperate across group boundaries. I estimate the treatment effects in the lab-in-the-field experiment with an OLS estimator given by $Y_{i}=\beta_{0}+\beta_{j} Z_{i, j}+\alpha_{n}+\alpha_{e}+\epsilon_{i}$, where $Y_{i}$ is the amount sent by the non-Tuareg Malian participant $i$ to their Tuareg partner and $Z_{i, j}$ indexes the $j$ treatment groups (with control as a reference group). Randomization occurred at the cluster level where the cluster was the enumerator-day. For this reason, I 
Figure 1: UN Treatment Increases Willingness to Cooperate

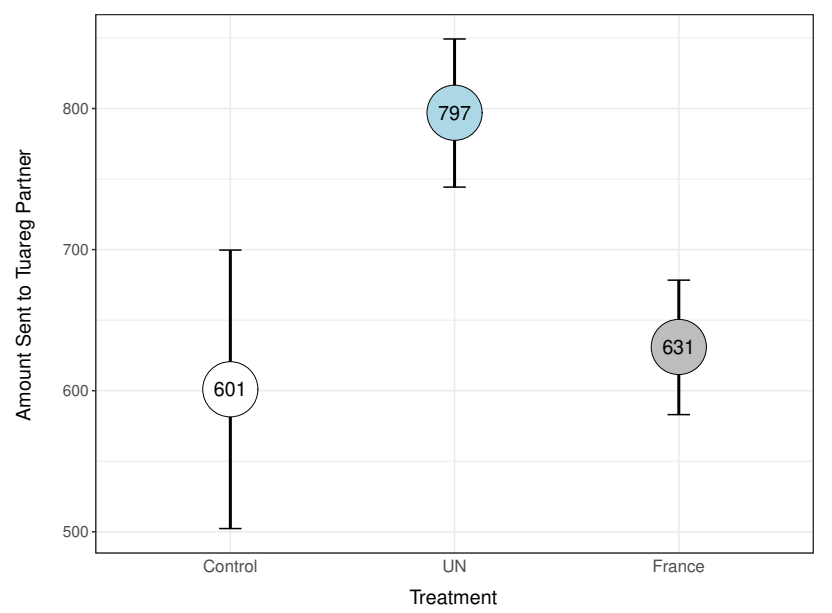

use robust cluster standard errors, which allow the error terms within the clusters to be related while assuming only that the error terms from different clusters are independent. In order to recuperate the efficiency losses from clustering and the inability to block-randomize the treatments, I estimate the average treatment effect with neighborhood fixed effects, denoted $\alpha_{n}$, and enumerator fixed effects, denoted $\alpha_{e}$. This estimation strategy allows for a conservative, theory-based improvement in precision without needing to include further covariates or alternative model specifications that may introduce bias due to overfitting (Gerber and Green 2012).

Figure 1 graphs the main results. Each of the three points in the figure presents the estimated amount sent to the Tuareg participants in each of the three treatment conditions (control, UN peacekeeping, and French enforcement). Participants assigned to control send an average of 601 or about $60 \%$ of their initial endowments to their Tuareg partners, reflecting the high level of baseline generosity of those Malians in the sample. However, those assigned to UN peacekeeping send 797 out of 1,000 FCFA to their Tuareg partners. This represents an increase of 196 FCFA or $32.6 \%$ compared to control, a substantive and statistically significant difference. Participants assigned to French peacekeeping send 631 out of 1,000 FCFA to their Tuareg partners. This corresponds to an increase of 30 FCFA or 5\% compared to control, 
Figure 2: UN Treatment Increases Willingness to Cooperate for Low Trust Individuals

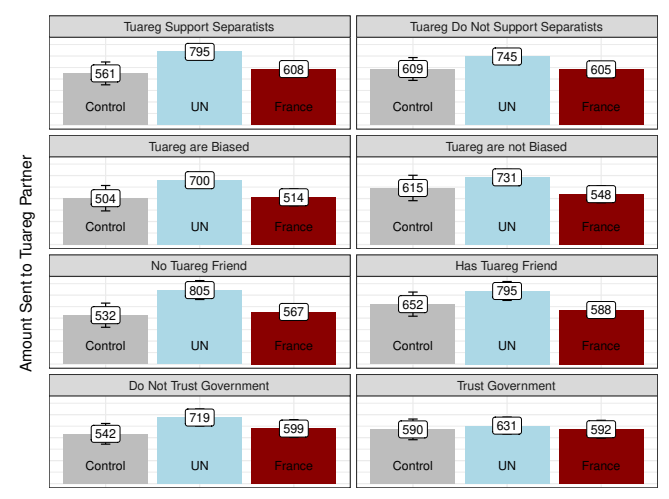

though the difference is not statistically distinguishable from zero. Moreover, the amount sent by participants in the UN treatment group differs to a substantively and statistically significantly extent from the amount sent by participants in the French treatment group.

The main results provide mixed evidence in favor of Hypothesis 1 and strong evidence in favor of Hypothesis 2. In line with Hypothesis 1, peacekeepers increase the willingness of participants to cooperate, though this effect is localized to the UN treatment. The difference between the UN and France treatment effects supports Hypothesis 2, which predicted that UN peacekeeping would be more effective than any peacekeeping by a single state. These findings are also in line with the expectations of the formal model with two exceptions. First, actual contributions across groups are higher than theorized, likely due to altruistic preferences not explicitly modeled. Second, the France treatment does not increase contributions relative to control. This lack of difference, along with the substantial difference between France and the UN, suggests that participants thought the peacekeepers would fine a relatively large range of contributions (see discussion of the cut-point parameter, $c$, above).

Next, I test observable implications derived from Hypothesis 3 that peacekeeping will have a greater effect on individuals with lower levels of baseline trust. In order to test this, I look at participants' responses to four pre-treatment questions that measure both social trust and institutional trust. For each of the four measures, I group together all low 
trust participants in one category and all high trust participants in another category (see Appendix B.4). Because levels of trust are not randomly assigned, I adjust for observable imbalances between high and low trust groups (see Appendix D.3).

Across all groups, the UN treatment increases willingness to cooperate for individuals with low trust but not for individuals with high trust, lending strong support to Hypothesis 3. The France treatment effect is statistically indistinguishable from zero across subgroups. To illustrate the differences in effects between low and high trust groups, Figure 2 graphs the estimated amount participants sent to their non-Tuareg partners in each treatment condition. On the left-hand side are each of the low trust groups and on the right-hand side are each of the high trust groups. For example, among those who believe that the majority of Tuareg support separatist groups (the first set of panels), participants assigned to UN peacekeeping send 795 out of 1,000 FCFA to their Tuareg partners. This represents an increase of 234 FCFA or $41.7 \%$ compared to control. However, among individuals who believe that most Tuareg do not support separatist groups, there is no statistically significant difference in the amounts sent in each treatment group. These results suggest that the effectiveness of peacekeeping is localized to individuals with little trust of other groups and institutions.

Finally, I test Hypothesis 4, which stated that contact with peacekeepers will make individuals more likely to trust the enforcement capacity and commitment of those peacekeepers. Figure 3 graphs the amount sent to the Tuareg partner as a function of contact with UN peacekeepers. I divide contact into three categories depending on quantity and quality of participants' contact with UN peacekeepers. I categorize participants who say they regularly see or speak to peacekeepers as being in "frequent contact." Individuals who occasionally saw peacekeepers but did not speak to them had "some contact." I categorized participants who did not regularly see or speak to peacekeepers as having "infrequent contact." Because contact with the UN is not randomly assigned, I adjust for observable imbalances between contact groups (see Appendix D.4). 
Figure 3: Amount Sent to Tuareg Partner, by Treatment and Contact with UN

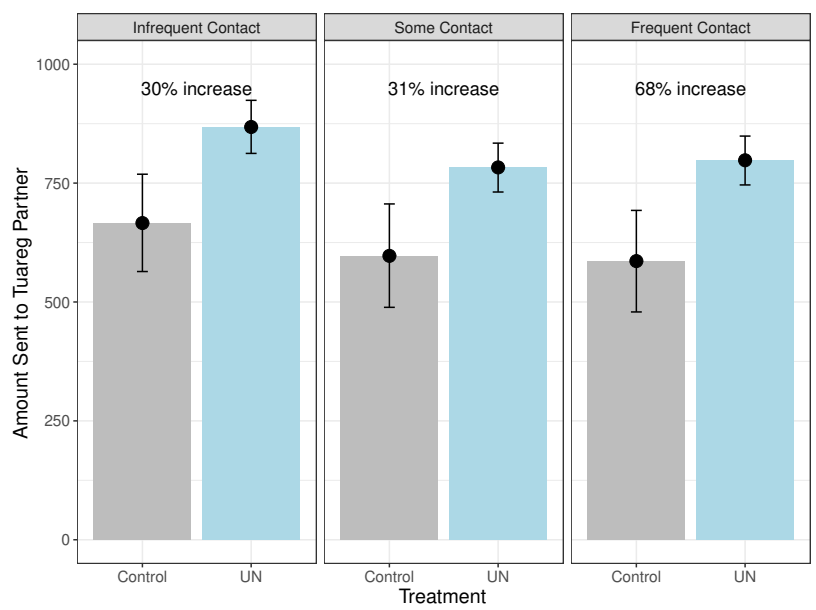

The results offer some evidence in favor of Hypothesis 4. Participants assigned to the UN treatment group demonstrate a greater willingness to cooperate than those assigned to control in all three subgroup categories. The absolute magnitude of the UN treatment effect does not appear to be correlated with individual contact with UN peacekeepers. However, UN peacekeeping increases average contributions by $68 \%$ relative to control for individuals in frequent contact with the UN, compared to $30 \%$ for individuals with infrequent contact and $31 \%$ for those with some contact, which supports the hypothesis. The difference in relative magnitude is due to the fact that individuals in frequent contact with the UN send less on average to Tuareg partners in the control group, suggesting that these individuals are the least likely to want to cooperate with members of other ethnic groups in the first place.

\section{Discussion: Investigating the Mechanisms}

The main results demonstrate that UN peacekeepers increase the willingness of non-Tuareg Malians to cooperate with Tuareg Malians in the form of contributions in a trust game but that French peace enforcers do not. I now turn to an investigation into the potential reasons for why this may be the case. I find evidence that perceptions of the UN as unbiased and France as biased account for the relative greater effectiveness of UN peacekeeping. Moreover, 
I show in Appendix A that there is little evidence in favor of other potential mechanisms. Although this analysis does not definitively rule out all other explanations, it does provide some suggestive findings that the bias mechanism is the primary channel through which UN peacekeeping increases willingness of Malians to cooperate across group boundaries. I disentangle these mechanisms using data from the lab experiment, interviews with participants of the lab experiment, and a follow-up survey.

Unbiased peacekeepers convince individuals to cooperate through a credible commitment to punish any potential party that transgresses in a social interaction. The unbiased peacekeeper will in the minds of the local population stop any violence, attack any perpetrators of violence, or detain survivors. By contrast, biased peacekeepers fail to reassure individuals that they will protect them from being taking advantage of by favored parties. Individuals from non-favored groups do not doubt that biased peacekeepers will punish them should they escalate a dispute (Favretto 2009). They doubt, however, whether biased peacekeepers will punish their favored group to protect non-favored civilians.

Some scholars argue that bias may actually improve an international actor's chances for promoting peaceful outcomes. According to this perspective, only biased peacekeepers can credibly convince their favored group about the resolve of other ethnic groups since they are effectively "on their side" (Kydd 2003; Savun 2008). Additionally, bias may reveal private information about a peacekeeper's willingness or resolve to enforce peace (Favretto 2009). Or, biased peacekeepers may have unique leverage over their favored parties, which they can use to promote peaceful outcomes (Zartman and Touval 1985). Bias is unlikely to help peacekeepers bolster intergroup cooperation, however. It is not clear why a biased peacekeeper would be able to influence the behavior of non-favored groups. Indeed, since they wish to achieve the best possible outcome for their favored group, non-favored groups will not take seriously private information held by biased peacekeepers. Similarly, biased peacekeepers will not hold any unique leverage over non-favored groups (Beber 2012, p. 
404). Moreover, while biased international actors may be well-suited to elite-level conflicts in which there exist informational asymmetries about relative power and resolve, they are less well-suited to local-level conflicts characterized by intergroup mistrust (Kydd 2006). In these cases, biased peacekeepers will support their favored side, regardless of trustworthiness, making them unreliable enforcers of communal interactions.

Skeptics question whether the UN is truly unbiased. Some suggest that UN impartiality is a "delusion" (Betts 1994). According to this line of thinking, when an actor invests as much human and financial capital in a post-conflict state as the UN does, it cannot maintain its impartiality (Lake 2016). It is also possible that the bias of the UN Security Council in favor of certain armed groups might manifest in perceptions of individual UN peacekeepers (Talentino 2007; Benson and Kathman 2014; Rhoads 2016). Research shows that member states use their position on the Security Council to influence where UN peacekeepers are posted (Mikulaschek 2017). However, these theories apply to political elites and armed groups rather than citizens disputing over local issues. In fact, existing research suggests that regular citizens in states with UN peacekeeping missions complain that the UN does too little rather than that it does too much (Kelmendi and Radin 2016).

Non-Tuareg Malians largely perceive the UN to be an unbiased international actor that does not favor any domestic groups. In order to systematically assess Malians' perceptions, I conducted a follow-up survey in July 2016 with 874 respondents in eight neighborhoods of Bamako and 12 rural villages in Central Mali. The survey asked the respondents whether they believed that the UN or France, respectively, was biased in favor of an ethnic group in Mali. $67 \%$ of all respondents said that they perceived of the UN as unbiased, compared to 41\% who perceived of France as unbiased, a substantively and statistically significantly lower proportion. Moreover, $38 \%$ said that France was biased in favor of the Tuareg compared to $27 \%$ who said that the UN was biased in favor of the Tuareg, a difference of $11 \%$, statistically significant at the .05 level. 
The results of this survey demonstrate that though most Malians perceive the UN as unbiased and more Malians see France as biased, a small proportion still perceive the UN as biased in favor of the Tuareg. This perceived bias likely stems from a combination of two factors. First, the UN peacekeeping operation has inevitably become entangled with the French military intervention. This association has compromised the UN's independence, at least in the mind of some Malians. Second, the UN peacekeeping operation in Mali has occasionally engaged in firefights with armed groups that have resulted in civilian casualties. As a result, Mali presents a least likely application of this mechanism - the UN will struggle to convince a part of the local population that it is unbiased and will enforce intergroup cooperation without favoring the Tuareg. If the analysis offers evidence in favor of the mechanism, I would expect it generalize to other settings as well.

Interviews with the participants of the experiment following the experiment demonstrate how these perceptions manifest in individual motivations. Some participants contrasted the UN to a colonial intervener. For example, a 22-year-old male participant said that he preferred the UN to France because "it did not colonize Mali and therefore will not target any interests (Participant DI6)." Others referenced the multi-national nature of UN peacekeeping operations as a consideration. Another 22-year-old man, who was assigned to the UN treatment and sent the Tuareg 750 FCFA, said that he preferred the UN "because it's an international institution specifically created to maintain peace (Participant CF12)." When asked whether he considered the UN to be unbiased and why, a 35-year-old male participant said that he believes the UN is unbiased because it is "supporting Mali, its role is to create an area of peace, dialogue, and reconciliation, and it's doing the job well (Participant BE21).”

These interviews also provide further evidence that the participants of the experiment perceived France as biased in favor of the Tuareg. For example, a 28-year-old man assigned to the French treatment that sent 400 FCFA to his Tuareg partner said that he did not think 
that France is unbiased because "it helps the Tuareg (Participant AE20)." Some specifically highlighted French alliances with Tuareg armed groups as a sign of persistent French bias. A 28-year-old man who sent 450 FCFA doubted that France is unbiased because "it supports the Tuareg rebels (Participant CH10)." A 51-year-old Malian man assigned to the French treatment who sent the Tuareg 500 FCFA, said that he does not trust France to manage the Malian crisis because "France supports the Tuareg rebels (Participant AG15)." Another participant, a 26-year-old man also assigned to the France treatment that sent his partner 350 FCFA, specifically identified French support of the Tuareg armed group Ansar Dine as a cause for concern (Participant DH13).

To more directly test whether the bias mechanism accounts for the effectiveness of the UN treatment relative to the French treatment, I asked each participant after the game-but before they were told about the final monetary outcome of the game - what they thought their Tuareg partner had sent back to them. According to the bias mechanism, participants assigned to the UN treatment should expect Tuareg Malians to cooperate more than those assigned to the France treatment because they perceive the UN as more unbiased than France. As a result, participants assigned to the UN should expect their Tuareg partners to return more than those assigned to France since they would believe that UN peacekeepers would punish low contributions by the Tuareg partner but French peacekeepers might not.

An analysis of participants' answers to this question reveals that participants assigned to the UN treatment believe that their Tuareg partners will send back more than those assigned to the France treatment. When assigned to French peace enforcement, participants believed, on average, that their Tuareg partner had returned 452 FCFA. However, when assigned to UN peacekeeping, participants believed, on average, that their Tuareg partner returned 556 FCFA, a difference of 104 FCFA or about $20 \%(p=0.0518)$. The difference in beliefs about the amount that the Tuareg partner would return are thus in line with the expectations of the bias mechanism. 


\section{Conclusion}

In this article, I argue that peacekeepers increase the willingness of individuals living in a post-conflict setting to cooperate with members of other social groups. I present evidence from a pre-registered lab-in-the-field experiment in Mali in line with this argument. I find that participants send more of their initial salary to partners when assigned to a treatment in which they are told that UN peacekeepers will punish any low contributions compared to control or to an identical French enforcement treatment. Furthermore, the results indicate that the UN is particularly effective among participants with low levels of social and institutional trust. Evidence from the experiment, interviews following the experiment, and a follow-up survey further suggest that the effectiveness of the UN is driven by the perception that the UN is more unbiased than France.

Given the challenging nature of peacekeeping operations in Mali, the logic of this argument likely generalizes to other peacekeeping setting involving different types of social groups. Applied beyond Mali, the main results of the study link the micro-level operations of UN peacekeepers with the robust macro-level finding in the scholarly literature that UN peacekeeping maintains order after conflict. The potential success of local-level peacekeeping also offer contributing countries an important rationale for maintaining operations abroad, a challenging electoral proposition in recent times (Marinov et al. 2015). The conditional aspects of the results - that the UN is more effective in low trust settings and with increased contact - could also help us understand failures of UN peacekeeping. In the Democratic Republic of Congo, UN peacekeepers have been notorious for not connecting with the local population, especially deep in those isolated areas (as in Kivu) where residents are distrustful of other ethnic groups and government institutions (Autesserre 2010).

Finally, the findings of this article also offer potentially important policy prescriptions for how international actors can effectively bolster intergroup cooperation on the ground. In particular, this study suggests that the United Nations, rather than a colonial intervener 
with a legacy of relations with local groups in the country, will be especially effective at this task. Although it is possible that other international organizations or countries without a colonial legacy may effectively promote intergroup cooperation as well, my analysis suggests that the UN has particular advantages. Moreover, local populations quickly start perceiving foreign military interveners as neo-colonial occupiers, as the United States experienced in Afghanistan and Iraq. For their part, UN operations should emphasize peacekeeper contact with local populations, especially those individuals isolated from other social groups and central governance institutions. Such peacekeeping can lay the foundation for sustainable peace in war-torn states such as Mali. Yet, in order to foster reconciliation in the long run, local societies must use the gains from UN-enforced cooperation to craft domestic institutions and restore social trust that can sustain peace even in the absence of peacekeepers.

\section{Acknowledgments}

I thank Vivek Ashok, Kate Baldwin, Rob Blair, Jaimie Bleck, Sarah Bush, David Carter, Alexandre Debs, Monica Duffy Toft, Jessica Gottlieb, Yvan Guichaoua, Gary King, Jiyoung Ko, Lucy Martin, Julia Morse, Molly Offer-Westort, Pia Raffler, Elana Resnick, Nicholas Sambanis, Neil Narang, Keith Schnakenberg, Jessica Steinberg, Peter Tinti, seminar participants at APSA, ISA, B-WGAPE, Harvard, Yale, Ohio State, and WUSTL as well as three anonymous reviewers and Courtenay Conrad at the Journal of Politics for excellent comments and suggestions on this article. Ipek Sener and Tony Yang provided excellent research assistance. Special thanks to Innovations for Poverty Action, Mali, particularly Kadidia Maiga, Alassane Koulibaly, Diakaridia Dao, Seydou Traore, Romuald Anago, and Nicolo Tomaselli. A previous version of this paper was circulated as Empirical Studies on Conflict Working Paper

\section{References}

Kenneth W Abbott and Duncan Snidal. Why states act through formal international organizations. Journal of conflict resolution, 42(1):3-32, 1998.

Severine Autesserre. The Trouble with the Congo: Local Violence and the Failure of International Peacebuilding. Cambridge University Press, New York, NY, 2010. 
Severine Autesserre. Peaceland: Conflict Resolution and the Everyday Politics of International Intervention. Cambridge University Press, 2015.

Kyle Beardsley. Agreement without Peace? International Mediation and Time Inconsistency Problems. American Journal of Political Science, 52(4):723-740, 2008.

Kyle Beardsley. Peacekeeping and the contagion of armed conflict. The Journal of Politics, 73(4):1051-1064, 2011.

Andrew Beath, Fotini Christia, and Ruben Enikolopov. Winning Hearts and Minds through Development. 2012.

Bernd Beber. International mediation, selection effects, and the question of bias. Conflict Management and Peace Science, 29(4):397-424, September 2012.

Michelle Benson and Jacob D Kathman. United nations bias and force commitments in civil conflicts. The Journal of Politics, 76(02):350-363, 2014.

Joyce Berg, John Dickhaut, and Kevin McCabe. Trust, reciprocity, and social history. Games and Economic Behavior, 10(1):122-142, July 1995.

Helen Bernhard, Ernst Fehr, and Urs Fischbacher. Group affiliation and altruistic norm enforcement. The American Economic Review, 96(2):217-221, 2006. ISSN 00028282.

Richard K Betts. The delusion of impartial intervention. Foreign Affairs, 73:20, 1994.

Robert A Blair. International intervention and the rule of law after civil war: Evidence from liberia. International Organization, 73(2):365-398, 2019.

Vincenzo Bove and Andrea Ruggeri. Peacekeeping effectiveness and blue helmets' distance from locals. Journal of Conflict Resolution, 63(7):1630-1655, 2019. 
Sarah Sunn Bush and Lauren Prather. Who's there? election observer identity and the local credibility of elections. International Organization, pages 1-34, 2018.

Kate M Carter and Scott Straus. Changing patterns of political violence in sub-saharan africa. In Oxford Research Encyclopedia of Politics. 2019.

Volha Charnysh, Christopher Lucas, and Prerna Singh. The ties that bind: National identity salience and pro-social behavior toward the ethnic other. Comparative Political Studies, 2015.

David C. Conrad and Djanka Tassey Conde. Sunjata: A West African Epic of the Mande Peoples. Hackett, 2004.

Benjamin Crost, Joseph Felter, and Patrick Johnston. Aid under fire: Development projects and civil conflict. American Economic Review, 104(6):1833-56, 2014.

Tiemoko Diallo and Adama Diarra. Five u.n. peackeepers killed by truck bomb, mortar fire in mali. Reuters, 2016.

Michael Doyle and Nicholas Sambanis. Making War and Building Peace: United Nations Peace Operations. Princeton University Press, Princeton, NJ, 2006.

Thad Dunning and Lauren Harrison. Cross-cutting Cleavages and Ethnic Voting: An Experimental Study of Cousinage in Mali, 2010.

Katja Favretto. Should peacemakers take sides? major power mediation, coercion, and bias. American Political Science Review, 103(02):248, 2009.

James Fearon and David D Laitin. Explaining Interethnic Cooperation. The American Political Science Review, 90:715-735, December 1996. 
James Fearon, Macartan Humphreys, and Jeremy Weinstein. How does development assistance affect collective action capacity? results from a field experiment in post-conflict liberia. American Political Science Review, 109(3):450-469, 2015.

Ernst Fehr and Urs Fischbacher. Third-party punishment and social norms. Evolution and Human Behavior, 25(2):63-87, 2004.

Hanne Fjelde, Lisa Hultman, and Desirée Nilsson. Protection through presence: Un peacekeeping and the costs of targeting civilians. International Organization, 73(1), 2019.

Virginia Page Fortna. Does Peacekeeping Work? Shaping Belligerents Choices after Civil War. Princeton University Press, 2008.

Alan S Gerber and Donald P Green. Field Experiments: Design, Analysis, and Interpretation. W.W. Norton \& Company, 2012.

Marin Gillier. La coopération dans le sahel: Une approache globale, 2015.

Michael J Gilligan, Benjamin J Pasquale, and Cyrus Samii. Civil War and Social Cohesion: Lab-in-the-Field Evidence from Nepal. American Journal of Political Science, 58(3):604$619,2014$.

Grant M Gordon and Lauren E Young. Cooperation, information, and keeping the peace: Civilian engagement with peacekeepers in haiti. Journal of Peace Research, 54(1):64-79, 2017.

James Habyarimana, Macartan Humphreys, Daniel N Posner, and Jeremy M Weinstein. Cooethnicity. Diversity and the Dilemmas of Collective Action. Russell Sage Foundation, New York, NY, 2009.

Lise Morjé Howard. Power in peacekeeping. Cambridge University Press, 2019. 
Lisa Hultman, Jacob D Kathman, and Megan Shannon. Peacekeeping in the Midst of War. Oxford University Press, 2020.

Human Rights Watch. Mali: Spate of Killings by Armed Groups. Technical report, 2017.

Patrick Hunnicutt and William G. Nomikos. Nationality, gender, and deployments at the local level: Introducing the radpko dataset. International Peacekeeping, 27(4):645-672, 2020.

William I Jones. The Mise and Demise of Socialist Institutions in Rural Mali. GeneveAfrique, 11:19-44, 1972.

Pellumb Kelmendi and Andrew Radin. Unsatisfied? public support for postconflict international missions. Journal of Conflict Resolution, 2016.

Jana Krause. Resilient communities: Non-violence and civilian agency in communal war. Cambridge University Press, 2018.

Andrew Kydd. Which Side Are You On? Bias, Credibility, and Mediation. American Journal of Political Science, 47(4):597-611, 2003.

Andrew H Kydd. When Can Mediators Build Trust? The American Political Science Review, 100(3):449-462, 2006.

David A Lake. The statebuilder's dilemma: on the limits of foreign intervention. Cornell University Press, 2016.

Jason Lyall, Graeme Blair, and Kosuke Imai. Explaining support for combatants during wartime: A survey experiment in afghanistan. American Political Science Review, 107(4): 679-705, 2013. 
Jason Lyall, Yang-Yang Zhou, and Kosuke Imai. Can economic assistance shape combatant support in wartime? experimental evidence from afghanistan. American Political Science Review, 114(1):126-143, 2020.

Nikolay Marinov, William G Nomikos, and Josh Robbins. Does electoral proximity affect security policy? The Journal of Politics, 77(3):762-773, 2015.

Kevin A. McCabe, Mary L. Rigdon, and Vernon L. Smith. Positive reciprocity and intentions in trust games. Journal of Economic Behavior $\&$ Organization, 52(2):267-275, October 2003.

Christoph Mikulaschek. The Power of the Weak: How Informal Power-Sharing Shapes the Work of the UN Security Council. Working Paper, March 2017. URL https://christophmikulaschek.com/wp-content/uploads/2018/09/Mikulaschek-2018_Power-of-

Eric Mvukiyehe and Cyrus Samii. The Subtle Micro-Effects of Peacekeeping. In American Political Science Association Conference Paper, pages 1-35, August 2010. URL http://papers.ssrn.com/sol3/papers.cfm?abstract_id=1642803\&download=yes.

William Nomikos. Mali Country Report: Risks from the EU's Southern Border. EU-LISTCO Project, January 2020a.

William G Nomikos. Why share? an analysis of the sources of post-conflict power-sharing. Journal of Peace Research, 2020b.

Stephanie Pezard and Michael Shurkin. Achieving Peace in Northern Mali: Past Agreements, Local Conflicts, and the Prospects for a Durable Settlement. RAND Corporation, 2015.

Daniel N Posner. Institutions and Ethnic Politics in Africa. Cambridge University Press, 2005. 
Emily Paddon Rhoads. Taking sides in peacekeeping: impartiality and the future of the United Nations. Oxford University Press, 2016.

Andrea Ruggeri, Han Dorussen, and Theodora-Ismene Gizelis. Winning the peace locally: Un peacekeeping and local conflict. International organization, 71(1):163-185, 2017.

Nicholas Sambanis, Jonah Schulhofer-Wohl, and Moses Shayo. Parochialism as a Central Challenge in Counterinsurgency. Science, 336(6083):805-808, 2012.

Burcu Savun. Information, bias, and mediation success. International Studies Quarterly, 52 (1):25-47, 2008.

Renard Sexton. Aid as a tool against insurgency: Evidence from contested and controlled territory in afghanistan. American Political Science Review, 110(4):731-749, 2016.

Hannah M Smidt. United nations peacekeeping locally: enabling conflict resolution, reducing communal violence. Journal of Conflict Resolution, 64(2-3):344-372, 2020.

Andrea Kathryn Talentino. Perceptions of peacebuilding: The dynamic of imposer and imposed upon. International Studies Perspectives, 8(2):152-171, 2007.

Stanley J Tambiah. Ethnic conflict in the world today. American ethnologist, 16(2):335-349, 1989.

Barbara F Walter. Committing to Peace: The Successful Settlement of Civil Wars. Princeton University Press, Princeton, New Jersey, 2002.

Susanna Wing. Making Sense of Mali. Foreign Affairs, 2013.

I. William Zartman and Saadia Touval. International mediation: Conflict resolution and power politics. Journal of Social Issues, 41(2):27-45, 1985. 


\section{Biographical Statement}

WILLIAM G. NOMIKOS is an ASSISTANT PROFESSOR OF POLITICAL SCIENCE at WASHINGTON UNIVERSITY IN ST. LOUIS, ST. LOUIS, MO 63130. 